\title{
Muğla Orman Bölge Müdürlüğü’nde orman yangını riskinin çok kriterli analizi ve haritalandırılması
}

\author{
Multi-criteria analysis and mapping of forest fire risk in Muğla Regional Directorate of \\ Forestry
}

\author{
Uğur BALTACI ${ }^{1}$ \\ Feriha YILDIRIM²
}

${ }^{1}$ Orman Genel Müdürlüğü, Ankara

${ }^{2}$ Gazi Üniversitesi, Ankara

Sorumlu yazar (Corresponding author) Uğur BALTACI

ugurbaltaci@ogm.gov.tr

Geliş tarihi (Received)

26.03.2020

Kabul tarihi (Accepted)

26.08.2020

Sorumlu editör (Corresponding editor)

Mustafa BATUR

mustafabatur01@ogm.gov.tr

Atıf (To cite this article): Baltacı, U, Y1ldırım, $\mathrm{F}$ . (2021). Muğla Orman Bölge Müdürlüğü'nde orman yangını riskinin cbs tabanlı çok kriterli analizi ve haritalandırılması . Ormancılık Araştırma Dergisi , 8 (1), 1-11

DOI: https://doi.org/10.17568/ogmoad.708385

\section{Öz}

Orman yangın riskinin CBS temelli ve çok kriterli analizi; orman yangını riskini etkileyen en önemli kriterlerin tanımlanması, değer aralıklarının ve risk sınıflarının belirlenmesi, kriterlerin karşılaştırılması ve sonuç olarak risk endeksi ve risk haritasının üretilmesi aşamalarından oluşmaktadır. Bu çalışmada, Muğla Orman Bölge Müdürlüğü'nde (OBM) orman yangını riskinin hesaplanabilmesi için son 10 yılda (2010-2019) meydana gelen orman yangınları CBS ile analiz edilmiş, bu analizler arazi çalışmaları ile desteklenmiş ve özgün bir risk kriterleri tablosu düzenlenmiştir. Sonuç olarak Muğla OBM için risk endeksi hesaplanarak bir orman yangını risk haritası oluşturulmuştur. Çalışmanın esas hedefi, Muğla OBM baz alınarak, Türkiye'de orman yangını riskinin analizinde daha doğru sonuçlar alınmasını sağlamak amacıyla ve arazi ölçümlerinin de yardımıyla mümkün olduğu kadar objektif kriter değerlendirmeleri yapılması konusunda bir model oluşturmaktır.

Anahtar Kelimeler: Muğla Orman Bölge Müdürlüğü, orman yangını riski, risk indisi, risk haritas1

\begin{abstract}
GIS-based and multi-criteria analysis of forest fire risk consists of defining the most important criteria affecting the risk of forest fire, determining the value ranges and risk classes, comparing the criteria and consequently producing the risk index and risk map. In this study, forest fires that occurred in the last 10 years (2010-2019) were analyzed with GIS in order to calculate forest fire risk in Muğla Regional Directorate of Forestry (RDF), these analyzes were supported by field studies and a specific risk criteria table was prepared. As a result, a forest fire risk map was created by calculating the risk index for the Muğla RDF. The main target of the study is to analyze the risk of forest fires in Turkey in order to provide more accurate results and help of the field studies to be done is to create a model for assessment of objective criteria as much as possible, based on Muğla RDF.
\end{abstract}

Keywords: Muğla Regional Directorate of Forestry, forest fire risk, risk index, risk map 


\section{Giriş}

İnsan faktörü göz ardı edildiğinde orman yangını, özellikle Akdeniz Havzasında ekosistemin bir parçası olarak kendine has döngülere sahip doğal bir olgu olarak görülebilir (Bilgili ve ark, 2001; Sağlam ve ark, 2008). Bununla birlikte, insan faaliyetlerinin günümüz yangın rejimleri üzerindeki doğrudan ve dolaylı etkisinin giderek artması, gelecekte gerçekleşecek olan yangın rejimi değişikliklerini öngörmeyi zorlaştırmaktadır (Archibald ve ark, 2013).

Yangınların ekolojik bir faktör olarak meydana getirdiği etki, ekosistemlerin yangın sonrası iyileşmesi şeklinde devam eden bir yeniden yapılanma sürecine neden olabileceği gibi (Doussi ve Thanos, 1994), ekosistemin çoğunlukla insandan kaynaklanan nedenlerle bozulması (degradasyonu) ve var olan floristik bileşim ve yapısal özelliklerden uzaklaşmasıyla da sonuçlanabilmektedir (Moreira ve Vallejo, 2009). Yani gerek iklim değişimi (Pausas, 2004) ve gerekse antropojen kaynaklı diğer değişimler (Pausas ve Keeley, 2014) bölgesel yangın rejimlerini belirgin olarak değiştirmektedir (Tavşanoğlu, 2017). Dolayısıyla insan ve insan faaliyetleri işin içine girdiğinde orman yangını, doğal döngünün dışında değerlendirilmesi gereken büyük bir afete dönüşebilmektedir.

Orman yangınlarıyla mücadele organizasyonlarının kaynakları sınırlıdır ve sınırlı kaynaklarla etkili mücadelenin yolu da uygun karar destek sistemlerini kullanmaktan geçmektedir (Mavsar ve ark, 2013). Orman yangınlar1 ile mücadelede kullanılacak en etkin karar destek sistemleri; kaynak organizasyonunun temellerini oluşturan tehlike ve risk tahmin sistemleridir (Van Wilgen ve Burgan, 1984; Taylor ve Alexander, 2003). Orman yang1n sorunlarının tam olarak değerlendirilmesi ve çözümlere ilişkin kararlar ancak bir yangın riski ha- ritalaması mevcutsa tatmin edici olabilir (Jaiswal ve ark., 2002).

Orman yangın riski yüksek bölgeler, yangının kolayca başlayabileceği, insan aktivitelerinin ormanla yakınlaştığ1 yerlerdir. Türkiye'de orman yangınlarının \%89'u insan faaliyetleri kaynaklı, sadece $\% 11$ 'i ise y1ldırım kaynaklıdır (OGM, 2020a). Yani aslında bu kriterler bize insanın ve insan faaliyetlerinin nerede ve ne yoğunlukta olduğunu da ifade etmektedir. Örneğin Türkiye'de orman yangınları en çok orman içi ya da yakınındaki tarımsal alanlar, yerleşim yerleri, enerji nakil hatları, kara ve demiryolları, maden sahaları, piknik alanları ve çöplüklerden başlamaktadır (OGM, 2020a). Bu unsurların tamamı insanın ve insan faaliyetlerinin yoğun olduğu yerlerdir. Orman yangını risk analizleri de aslında bu ilişkiyi baz alarak insan faaliyetlerinin orman yangınına sebep olma eğilimini yoğunluk olarak ifade etmektedir.

Bu çalışmanın amacı; Muğla Orman Bölge Müdürlüğ̈̈'nde (OBM) son 10 yılda meydana gelen orman yangınlarını CBS ile analiz etmek suretiyle daha objektif ve özgün bir risk kriterleri tablosu oluşturmak ve risk endeksini hesaplayarak orman yangını riskini temsil edecek bir harita ortaya koyabilmektir.

\section{2. Çalışma Alanı}

Araştırmanın konusunu teşkil eden Muğla OBM; Orman Genel Müdürlüğü'nün (OGM) ülke genelindeki 28 orman bölge müdürlüğünden biri olup Aydın ve Muğla ili mülki sınırlarını kapsamaktadır. Kuzeyinde İzmir OBM, doğusunda Denizli ve Antalya OBM, güneyinde Akdeniz, batısında ise Ege denizi yer almaktadır (Şekil 1). Muğla OBM toplam alan1 2 milyon 51 bin 212 hektar olup toplam ormanlık alanı 1 milyon 158 bin 925 hektardır (URL-1).

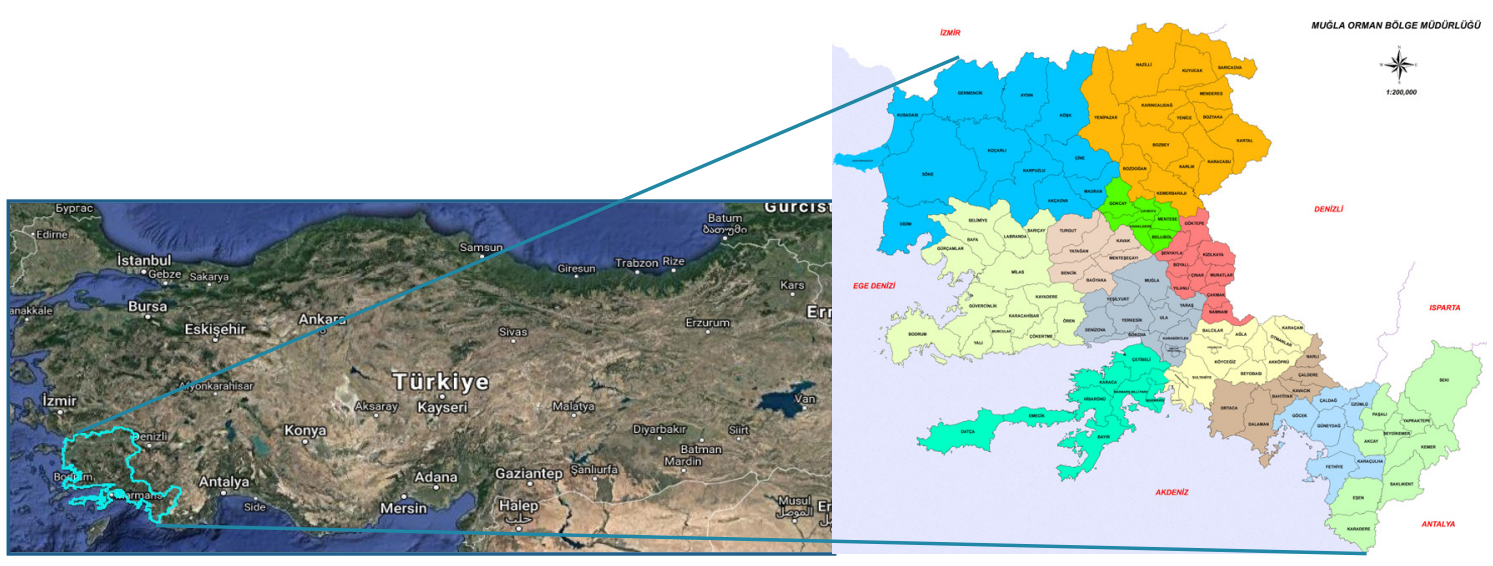

Şekil 1. Muğla Orman Bölge Müdürlüğü

Figure 1. Mugla Regional Directorate of Forestry 
Muğla OBM idari olarak 12 adet Orman İşletme Müdürlüğü (Aydın, Nazilli, Dalaman, Fethiye, Kemer, Köyceğiz, Marmaris, Muğla, Kavaklıdere, Yatağan, Milas ve Y1lanlı) ile 74 adet Orman İşletme Şefliğinden oluşmaktadır (URL-2).

Çalışma alanında bir yandan tarımsal faaliyetlerin çeşitliliği, bu faaliyetlerin yıl boyu devam etmesi ve tarım alanlarının ormanla iç içe bulunması, diğer yandan ise ülkemizin en gözde turistik bölgelerinden biri olması sebepleriyle insan kaynaklı orman yangınları açısından büyük bir risk bulunmaktadır. Ayrıca orman içerisindeki maden ocağı sayısının fazla olması, orman içi ve yakınındaki turistik tesislerin ve yapılaşmanın ciddi boyutlara ulaşması, orman içine yapılmış vahşi çöp depolama alanlarının artması, orman içerisinden geçen enerji nakil hatları, sayısı her geçen yıl artan rüzgar tribünleri ve bölgenin rant açısından çok büyük değer taşıması da ormanları tehdit eden faktörlerdendir.

\section{Materyal ve Yöntem}

\subsection{Materyal}

Orman yangını riskinin analizi için çalışma alanına ait topoğrafya, bitki örtüsü ve insan faaliyetleri (arazi kullanımı) verilerinden yararlanılmıştır. 1/25.000 ölçekli sayısal topoğrafya paftaları kullanılarak eğim (Şekil 2), bakı (Şekil 3) ve rakım (Şekil 4) haritaları oluşturulmuştur. Bitki örtüsünü temsil eden ağaç türü (Şekil 5), kapalılık (Şekil 6) ve çağ sınıfları (Şekil 7) haritaları, OGM sayısal meşcere haritalarından üretilmiştir. İnsan faaliyetlerini (arazi kullanımını) temsil edecek yol ağı, tarım alanları, iskân alanları ve enerji nakil hatları verileri ise OGM veri tabanında mevcut sayısal altlıklar ve web servisler kullanılarak elde edilmiştir. Verilerin analizi, modellenmesi ve sonuç haritalarının üretilmesi için ArcGIS 10 programı kullanılmıştır.

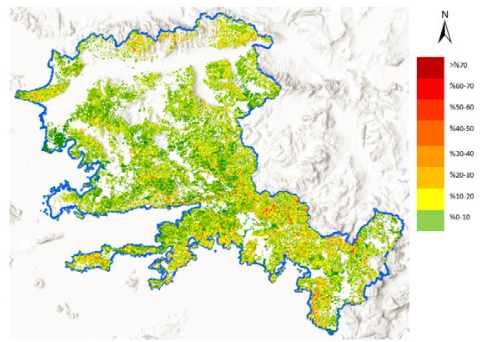

Şekil 2. Eğim haritası Figure 2. Slope map

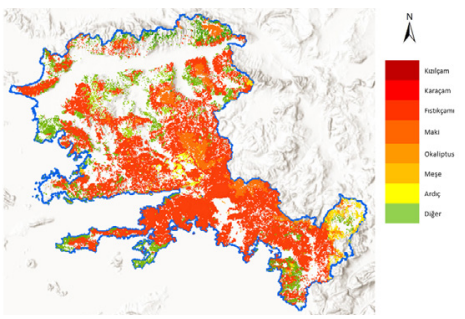

Șekil 5. Ağaç türleri haritası Figure 5. Tree species' map

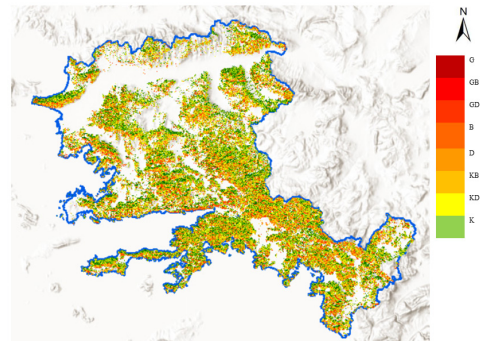

Sekil 3. Bak1 haritası Figure 3. Aspects map

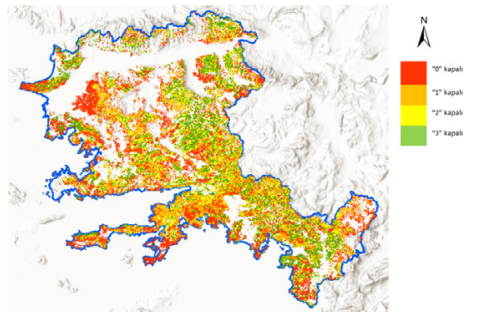

Şekil 6. Orman kapalılık haritası Figure 6. Crown closure map

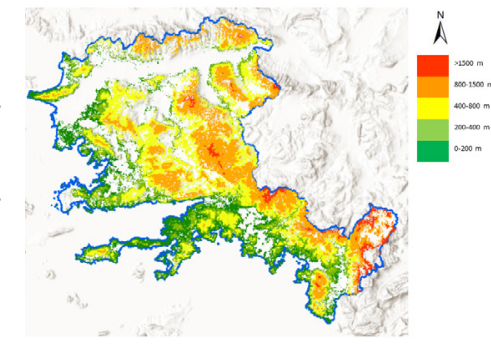

Sekil 4. Rakım haritası Figure 4. Altitude map

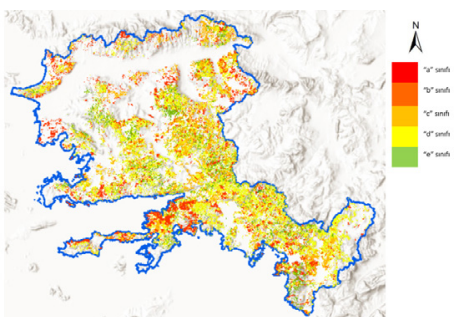

Şekil 7. Orman çağ sınıfları haritası Figure 7. Tree development stages

\subsection{Yöntem}

Orman yangını riski, bir alanda çeşitli kriterlerin bir araya gelerek orman yangını çıkmasına neden olma ihtimalini ifade etmektedir. Orman yangını riskini analiz edecek model; değişkenleri belirlemek, değişkenler arasındaki ilişkileri incelemek ve risk indeksini hesaplayacak eşitliği oluşturmak üzere kurulmuştur.

Bitki örtüsünün ve topografik kriterlerin orman yangını üzerindeki etkisini tespit etmek üzere son
10 yılda (2010-2019) Muğla OBM'nde meydana gelmiş orman yangınlarının (OGM, 2020b) yangın başlangıç noktaları CBS ile analiz edilmiștir. Böylece ağaç türü, kapalılık, çağ sınıfları, eğim, bakı ve rakım kriterlerinin orman yangını riskine etkileri belirlenmiştir.

İnsan faaliyetlerinin (arazi kullanımı) orman yangını riski üzerindeki etkisini tespit etmek üzere önce son 10 yılda (2010-2019) orman yangınlarının (OGM, 2020b) çıkış sebepleri analiz edilmiştir. Ardından uzaklık kriterlerinin değer aralıkları 
belirlenmek üzere Muğla OBM'nde 2019 yılında meydana gelen orman yangınlarından 12 adedi üzerinde arazi çalışmaları yapılmıştır. Böylece insan faaliyetlerinin orman yangını riskine etkileri belirlenmiştir.

Oluşturulan kriter tablosunda tüm kriterlere yangın riskine etkisi ölçüsünde risk faktörleri atanmıştır. En etkili ölçü " 5 ", en düşük etkiye sahip ölçü de " 1 " ile ifade edilmiştir. Ağırlıklar belirlenirken Erten ve arkadaşlarının (2005) kriter tablosundaki ağırlık değerleri baz alınmıştır. Bu çalışmada kriter ağırlığı olarak bitki örtüsü kriterleri için "7", topoğrafik kriterler için " 5 "ve insan faaliyetlerine mesafe kriterleri için " 3 ” değeri kullanılmaktadır.

$\mathrm{Bu}$ çalışmaların ardından orman yangını indeksini hesaplamak için kullanılacak denklem düzenlenmiştir. Bu denklem Erten ve arkadaşlarının (2005) orman yangını risk indeksini hesaplamakta kullandıkları denklemi baz almaktadır.

\section{Bulgular}

\subsection{Kriterlerin değerlendirilmesi}

\subsubsection{Bitki örtüsü}

Orman yangını için bitki örtüsü yakıt demektir ve bitki örtüsünün çeşidi, karışımı, yoğunluğu, kapalılığ 1 ve gelişim çağları orman yangını riskini doğrudan etkileyen parametrelerdir. Muğla OBM'nde son 10 yılda 2.889 adet orman yangını meydana gelmiştir (OGM, 2020c). Bu yangınların 2.571 adedi insan faaliyetleri kaynaklı ve kalan 318 yangın yıldırım kaynaklıdır (OGM, 2020a). İnsan kaynaklı 2.571 orman yangını CBS ile analiz edilerek ağaç türü, kapalılık ve çağ sınıfları kriterlerinin orman yangını riskine etkisi ortaya konmuştur.

\subsubsection{Ana ağaç türü}

Ağaç türü, orman yangınlarının başlangıç noktasını ve yangı̀n davranışını belirleyen en önemli unsurlardan birini oluşturur. Özellikle kızılçam gibi iğne yapraklı ve kuru karakterdeki türler yangın için uygun koşullar oluştururken, kayın gibi geniş yapraklı ve nemli türler zor yanan ve yangını engelleyici bir özellik gösterirler (Karabulut ve Karakoç, 2013).

Çalışma alanında meydana gelen 2.571 adet orman yangını başlangıç noktalarına ve ağaç türüne göre analiz edilmiştir (Tablo 1). Analiz sonucuna göre çalışma alanında yangına en hassas tür kızılçamdır; onu karaçam, fıstıkçamı ve maki izlemektedir.

Tablo 1. a) Son 10 yılda (2010-2019) meydana gelen insan kaynaklı orman yangınlarının başlangıç noktalarına göre ağaç türüne bağlı risk etki analizi, b) risk haritası (OGM, 2020b)

Table 1. a) Risk impact analysis depending on tree type according to the starting points of human-borne forest fires that occurred in the last 10 years (2010-2019), b) risk map (OGM, 2020b)

(a)

\begin{tabular}{lccc}
\hline Ağaç türü & Adet & \% Oran & Risk puan1 \\
\hline Kızılçam & 1750 & 68 & 5 \\
Karaçam & 254 & 10 & 4 \\
Fistıkçamı & 148 & 6 & 3 \\
Maki & 141 & 5 & 3 \\
Okaliptus & 91 & 4 & 2 \\
Meşe & 71 & 3 & 2 \\
Diğer türler & 42 & 2 & 1 \\
\hline
\end{tabular}

\subsubsection{Kapalılık}

Kapalılık bir meşcerenin tepe yoğunluğunu ifade ederken, farklı kapalılık dereceleri meşcere altında farklı etkilere yola açmaktadır. Meşcere (orman) kapalılığının sıkışık olması durumunda toprak yüzeyine yeterli miktarda 1 şı ve sıcaklık giremez. Düşük 1şıkta ve düşük sıcaklık derecesinde toprak yüzeyinde kalın bir ölü örtü (ot-yaprak-ibre-kuru dal) tabakası oluşur. Çünkü bu koşullarda ölü örtüyü ayrıştırabilecek olan mikroorganizma faa- (b)

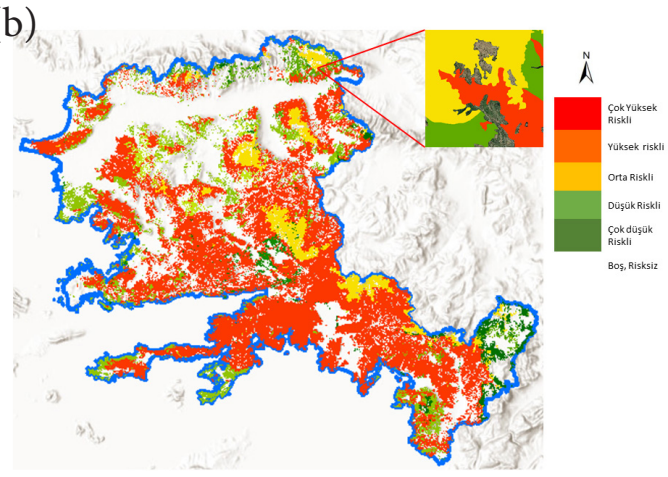

liyetleri yeterince gerçekleşmez. Ölü örtü ayrışıp toprağa dönüşemediği gibi, toprak üzerinde sürekli nemli bir tabaka oluşur. Açık alanlarda ayrıca otsu ve odunsu diri örtü gelir. Kapalılığın düşük olduğu yerlerde ise ölü örtü ayrışamadan rüzgarlar arac1lığ1 ile savrulup gider. Toprakta kurumalar ve azot bakımından fakirleşmeler görülebilir. Ancak 1 şık ve sıcaklık yeterli olduğundan daha fazla diri örtü bulunur. Normal kapalı meşcerelerde sık kapalı meşcereler altındaki kadar ölü örtü birikimi olmaz ve düşük kapalı meşcereler altındaki kadar diri örtü 
birikimi olmaz (Genç, 2012). Yani kapalılık yanıcı maddenin çeşidini, nemini ve yoğunluğunun etkileyen bir kriterdir.

Çalışma alanında son 10 yılda meydana gelen insan kaynaklı orman yangınlarının başlangıç noktaları CBS ile analiz edilmiştir (Tablo 2). Analiz sonucuna göre çalışma alanında yangına en hassas kapalılık derecesinin “3- sıkışık kapalı” olduğu anlaş1lmaktadır.

Tablo 2. a) Son 10 yılda (2010-2019) meydana gelen insan kaynaklı orman yangınlarının başlangıç noktalarına göre meşcere kapalılı̆̆ına bağlı risk etki analizi, b) risk haritası (OGM, 2020b)

Table 2. a) Risk impact analysis based on stand crown closure according to the starting points of human-borne forest fires that occurred in the last 10 years (2010-2019), b) risk map (b) (OGM, 2020b)

(a)

\begin{tabular}{lccc}
\hline Kapalılık & Adet & \% Oran & Risk puanı \\
\hline Sıkışık kapalı (3) & 952 & 37 & 5 \\
Işıklı kapalı (0) & 565 & 22 & 4 \\
Normal kapalı (2) & 540 & 21 & 3 \\
Gevşek kapalı (1) & 514 & 20 & 2 \\
\hline
\end{tabular}

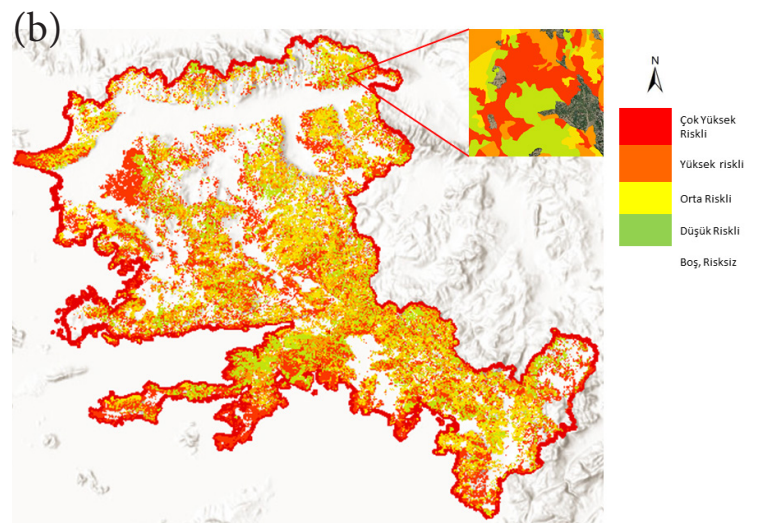

\subsubsection{3. Çağ sınıfları}

Meşcere gelişim çağları; ormanı meydana getiren ağaçların yer yüzeyinden $1,30 \mathrm{~m}$ yüksekliğindeki çapları (Orta çap) dikkate alınarak oluşturulmuş bir sınıflandırmadır. Meşcere gelişme çağları bakımından; a: 1,30 m çapları 7,9 cm'ye kadar olanlar "gençlik ve sıklık", b: 1,30 m çapları 8-19,9 cm arasındakiler "s1rıklık ve direklik", c: 1,30 m çapları 20-35,9 cm arasındakiler "ince ağaçlık”, d: 1,30 m çapları 36-51,9 cm

arasındakiler "orta ağaçlık", e: 1,30 m çapları $52 \mathrm{~cm}$ ve daha kalın çaplılar "kalın ağaçlık" çağı şeklinde sınıflandırılmaktadır (Genç, 2012).

Çalışma alanında son 10 yılda meydana gelen insan kaynaklı orman yangınlarının başlangıç noktaları CBS ile analiz edilmiştir (Tablo 3). Analiz sonucuna göre çalışma alanında yangına en hassas çağ sınıfının "b-sıklık ve direklik çağı” olduğu anlaşılmaktadir.

Tablo 3. a) Son 10 yılda (2010-2019) meydana gelen insan kaynaklı orman yangınlarının başlangıç noktalarına göre çağ sınıflarına bağlı risk etki analizi, b) ve risk haritası (OGM, 2020b)

Table 3. a) Risk impact analysis based on development stages according to the starting points of human-borne forest fires that occurred in the last 10 years (2010-2019), b) risk map (OGM, 2020b)

(a)

\begin{tabular}{lrrc}
\hline Çağ sınıfları & Adet & \% Oran & Risk puanı \\
\hline b: "sırıklık ve direklik" & 1124 & 43,73 & 5 \\
c: "ince ağaçlık" & 713 & 27,72 & 4 \\
a: "gençlik ve sıklık" & 530 & 20,63 & 3 \\
d: "orta ağaçlık" & 201 & 7,81 & 2 \\
e: "kalın ağaçlık" & 3 & 0,11 & 1 \\
\hline
\end{tabular}

\subsubsection{Topoğrafik kriterler}

\subsubsection{1. Ĕ̆im}

Jaiswal ve arkadaşlarından (2002) günümüze kadar tüm çalışmalar eğimin yangın riski üzerinde (b)

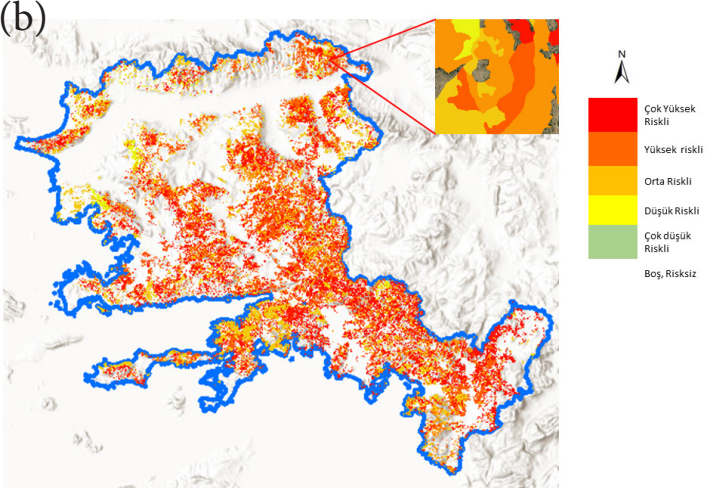

doğrusal bir etkisi olduğunu, eğim arttıkça yangın riskinin de arttığını ifade etmektedir (Erten ve ark, 2004 ve 2005; Sağlam ve ark, 2008; Karabulut ve ark, 2013; Sivrikaya ve ark, 2014; Akay ve ark, 
2019). Oysa orman yangınlarının yaklaşık \% $\% 0^{\prime} 1 \mathrm{lk}$ bölümü insanlar ve insan faaliyetleri sebebiyle çıkmakta (OGM, 2020a), insanlar da yerleşim ve çalışma için mümkün olduğu kadar düşük eğimli arazileri tercih etmektedirler. Çünkü eğim arttıkça hem maliyetler, hem de iş gücü artmaktadır. Yani orman yangınının en büyük nedeni olan insan ve insan faaliyetleri düşük eğimli alanlarda yoğunlaş- maktadir

Çalışma alanında son 10 yılda meydana gelmiş olan insan kaynaklı orman yangınları başlangıç noktalarına göre CBS ile analiz edilmiştir (Tablo 4). Analiz sonucuna göre çalışma alanında yangına en hassas alanların yaklaşık \%73 oranında \%0-20 eğim aralığında bulunduğu anlaşılmaktadır.

Tablo 4. a) Son 10 yılda (2010-2019) meydana gelen insan kaynaklı orman yangınlarının başlangıç noktalarına göre eğime bağlı risk etki analizi, b) risk haritası (OGM, 2020b)

Table 4. a) Risk impact analysis based on slope according to the starting points of human-borne forest fires in the

(a)

\begin{tabular}{lrrc}
\hline Eğim (\%) & Adet & \% Oran & Risk puan1 \\
\hline $0-10$ & 1042 & 40,53 & 5 \\
$11-20$ & 837 & 32,57 & 5 \\
$21-30$ & 361 & 14,06 & 3 \\
$31-40$ & 182 & 7,09 & 2 \\
$41-50$ & 82 & 3,19 & 2 \\
$51-60$ & 41 & 1,59 & 1 \\
$61-70$ & 16 & 0,62 & 1 \\
$71-80$ & 6 & 0,22 & 1 \\
$81-90$ & 2 & 0,09 & 1 \\
$>91$ & 1 & 0,04 & 1 \\
\hline
\end{tabular}

\subsubsection{Bakı}

Bakı, güneşlenme süresinin bir ifadesidir. Kuzey yarım kürede güneşlenme süresi, yani solar radyasyona maruz kalma süresi en yüksek bakılar sırasıyla güney ve batı bakılardır. Sırasılla doğu ve kuzey bakılarda ise güneşlenme süresi daha düşüktür (Skidmore, 1997). İnsanlar tarih boyunca gida

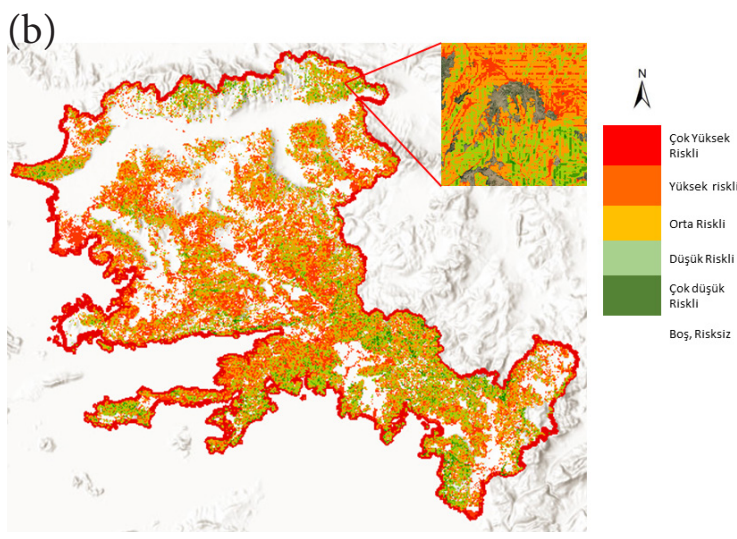

saklama dışında güney bakıları tercih etmişlerdir.

Çalışma alanında son 10 yılda meydana gelmiş olan insan kaynaklı orman yangınları, başlangıç noktalarına göre CBS ile analiz edilmiştir (Tablo 5). Analiz sonucuna göre çalışma alanında yangına en hassas alanların yaklaşık \%44 oranında güneyli bakılarda bulunduğu anlaşılmaktadır.

Tablo 5. a) Son 10 yılda (2010-2019) meydana gelen insan kaynaklı orman yangınlarının başlangıç noktalarına göre bakıya bağlı risk etki analizi, b) risk haritası (OGM, 2020b)

Table 5. a) Risk impact analysis based on aspect according to the starting points of human-borne forest fires in the last 10 years (2010-2019), b) risk map (OGM, 2020b)

(a)

\begin{tabular}{crrc}
\hline Bak1 & Adet & \% Oran & Risk puan1 \\
\hline G & 428 & 16,67 & 5 \\
GB & 351 & 13,67 & 5 \\
GD & 341 & 13,45 & 5 \\
B & 338 & 13,30 & 4 \\
D & 318 & 12,38 & 3 \\
KB & 292 & 11,36 & 2 \\
KD & 254 & 9,88 & 2 \\
K & 239 & 9,29 & 1 \\
\hline
\end{tabular}

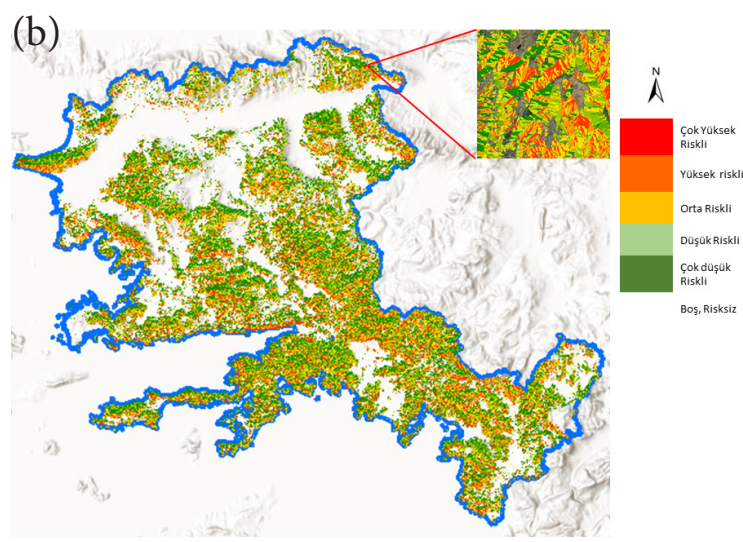




\subsubsection{Rakım}

İnsanoğlu, dünya üzerinde rakımın 0 m olduğu sahillerden ekstrem rakımlara kadar her yükseltiye yayılmış ve adapte olmuşsa da insanlar ve faaliyetleri, yaşam koşullarının daha az zorlayıcı olması nedeniyle yoğun olarak 0-1.500 m arasında yer almaktadır. Bitki örtüsü ise rakıma göre çeşitlilik ve yoğunluk gösterir.

Çalışma alanında son 10 yılda meydana gelmiş olan insan kaynaklı orman yangınları başlangıç noktalarına göre CBS ile analiz edilmiştir (Tablo 6). Analiz sonucuna göre çalıșma alanında yangına en hassas alanların yaklaşık \%64 oranında 0-400 m arası yükseltide bulunduğu anlaşılmaktadır.

Tablo 6. a) Son 10 yılda (2010-2019) meydana gelen insan kaynaklı orman yangınlarının başlangıç noktalarına göre rakıma bağlı risk etki analizi, b) risk haritası (OGM, 2020b)

Table 6. a) Risk impact analysis based on altitude according to the starting points of human-borne forest fires in the last 10 years (2010-2019), b) risk map (OGM, 2020b)

(a)

\begin{tabular}{lrrc}
\hline Rakım (m) & Adet & Oran (\%) & Risk puan1 \\
\hline $0-400$ & 1654 & 64,33 & 5 \\
$401-1000$ & 657 & 25,57 & 3 \\
$1000-1500$ & 171 & 6,64 & 2 \\
$>1500$ & 89 & 3,46 & 1 \\
\hline
\end{tabular}

\subsection{3. İnsan faaliyetlerine mesafe kriterleri}

\subsubsection{Tarım alanlarına mesafe}

Orman yangınlarının en büyük sebeplerinden biri tarımsal faaliyetler sirasında yapılan dikkatsizlikler ve kazalardır. Her yıl ormana sirayet edenlerin yanında ormana geçmeden söndürülen birçok ziraat yangını mevcuttur. Anız yakma, bağ-bahçe te-

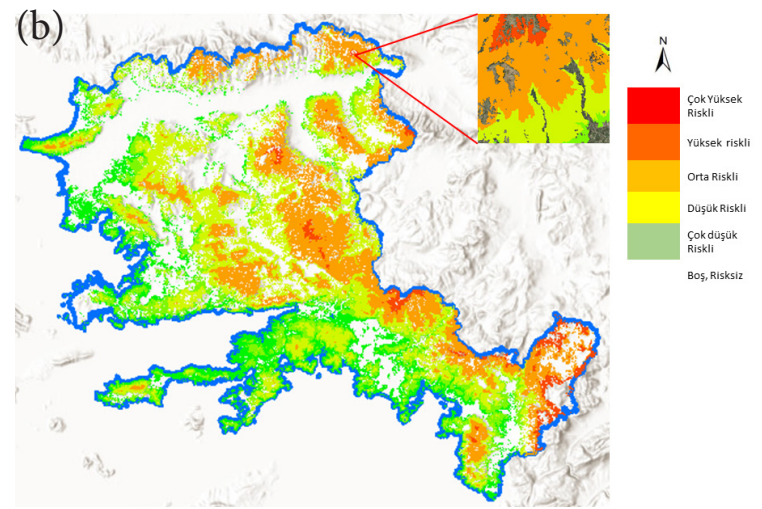

mizliği ve sera temizliği başlıca tarımsal kaynaklı orman yangını sebepleridir.

Muğla OBM'nde yapılan arazi çalışmalarında tarım arazileri kaynaklı orman yangınları için en riskli zonun 0-25 m arasında olduğu tespit edilmiştir (Tablo 7). Ancak rüzgârın da etkisiyle ormana $1000 \mathrm{~m}$ mesafede çıkan bir ziraat yangınının da kolayca ormana sirayet edebildiği bilinmektedir.

Tablo 7. a) Orman-Tarım alanları mesafesine göre risk durumu, b) risk zonları haritası Table 7. a) Risk status according to the distance of forest-agricultural areas, b) risk zones map

(a)

\begin{tabular}{cc}
\hline Orman-Ziraat mesafesi & Risk puan1 \\
\hline $0-25 \mathrm{~m}$ & 5 \\
$25-100 \mathrm{~m}$ & 3 \\
$100-500 \mathrm{~m}$ & 2 \\
$500-1000 \mathrm{~m}$ & 1 \\
\hline
\end{tabular}

\subsubsection{Yerleșim yerlerine mesafe}

Yerleşim alanlarındaki insan faaliyetleri orman yangını risklerini önemli ölçüde artırabilir. $\mathrm{Bu}$ nedenle Muğla OBM'nde yerleşim yeri kaynaklı orman yangınları yerinde incelenmiştir. Yapılan

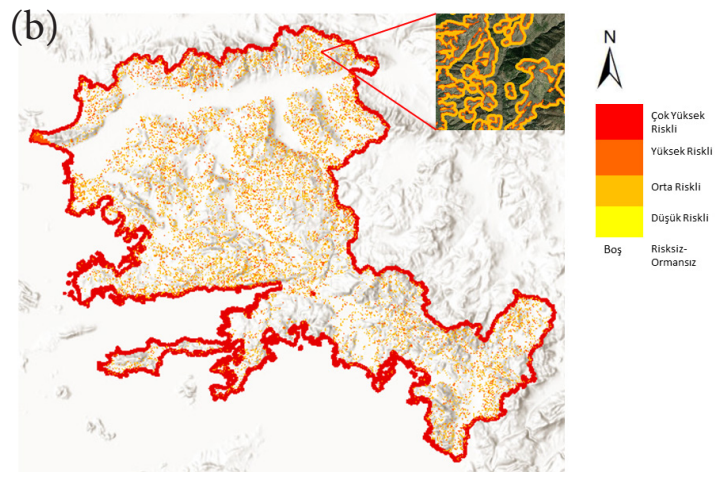

değerlendirmede en riskli zonun 0-50 m olduğu ve yerleşim yeri kaynaklı yangınların çoğunun bu zonda meydana geldiği görülmüştür (Tablo 8). 50$200 \mathrm{~m}$ arası ise ikinci derece riskli zon olarak görülmektedir. 
Tablo 8. a) Orman-Yerleşim yerleri mesafesine göre risk durumu, b) risk zonları haritası Table 8. a) Risk situation according to the distance of forest-settlement areas, b) risk zones map

(a)

\begin{tabular}{cc}
\hline $\begin{array}{c}\text { Orman-Yerleşim yeri } \\
\text { mesafesi }\end{array}$ & Risk puanı \\
\hline $0-50 \mathrm{~m}$ & 5 \\
$50-200 \mathrm{~m}$ & 3 \\
$200-500 \mathrm{~m}$ & 2 \\
\hline
\end{tabular}

\subsubsection{Yollara mesafe}

Orman yangınlarının çok büyük bir bölümü insan faaliyetlerinden kaynaklanmaktadır. Yollar da insan faaliyetlerinin vazgeçilmez araçlarıdır. Türkiye genelinde 2010-2019 döneminde çıkmıș 24.773 orman yangınından çıkış noktası verisi bulunan 7.766 adet orman yangını (OGM, 2020b) CBS olarak analiz edildiğinde neredeyse tüm orman yan-

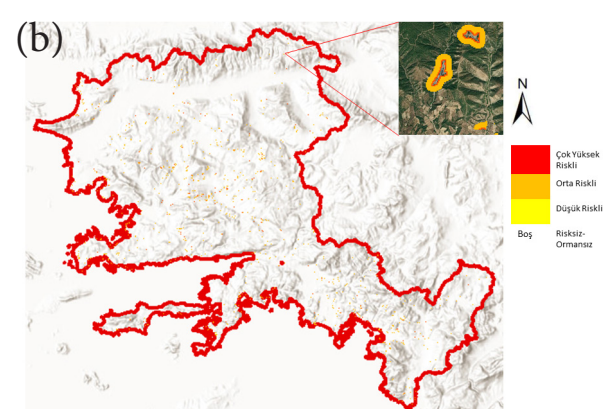

gınlarının başlangıç noktalarının yollara çok yakın olduğu görülmektedir.

Muğla OBM'nde yapılan arazi çalışmaları ile son 2 yılda çıkmış olan orman yangınları yerinde incelenmiştir. Yollar kaynaklı orman yangınlarının neredeyse tamamının yola 0-25 m mesafede çıktığ 1 görülmüştür (Tablo 9). İkinci derecede riskli zon 25-100 m arasidır.

Tablo 9. a) Orman-Yol mesafesine göre Risk Durumu, b) risk zonları haritas1 Table 9. a) Risk Status by Forest-Road distance, b) risk zones map

(a)

\begin{tabular}{lc}
\hline Orman-Yol mesafesi & Risk puanı \\
\hline $0-25 \mathrm{~m}$ & 5 \\
$25-100 \mathrm{~m}$ & 3 \\
$100-500 \mathrm{~m}$ & 2 \\
\hline
\end{tabular}

\subsubsection{Enerji nakil hatlarma mesafe}

Ülkemizde köylerin çoğu orman içerisinde dağıllmış şekilde yer almaktadır. Ayrıca iller ve ilçeler arası enerji nakil hatları ülkemizde mülkiyet sorunları nedeniyle orman içerisinden geçirilmektedir. Enerji dağıtım şirketleri orman içerisinden geçen nakil hatlarının alt temizliğini ve bakımlarını

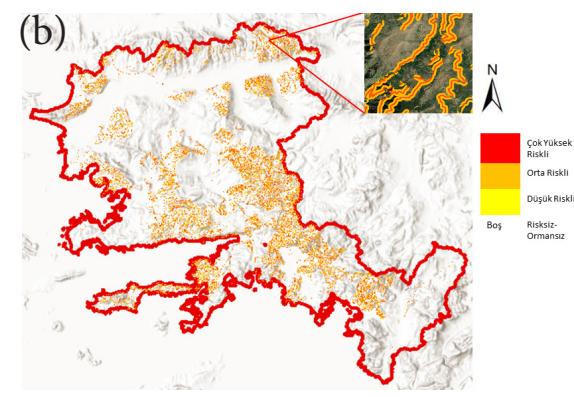

yapmakla mükelleftirler. Buna rağmen her yıl bakımsız enerji nakil hatlarından ve hatların geçtiği güzergâhın bakımsız olmasından kaynaklı pek çok orman yangını meydana gelmektedir.

Muğla OBM'nde enerji nakil hatları (ENH) kaynaklı çıkmış orman yangınları incelendiğinde, çoğu yangının hemen enerji nakil hattı altında baş-

Tablo 10. a) Orman-ENH mesafesine göre Risk Durumu, b) risk zonları haritası Table 10. a) Risk Status by Forest-ETL distance, b) risk zones map

(a)

\begin{tabular}{cc}
\hline Orman-ENH mesafesi & Risk puan1 \\
\hline $0-10 \mathrm{~m}$ & 5 \\
$10-50 \mathrm{~m}$ & 3 \\
\hline
\end{tabular}

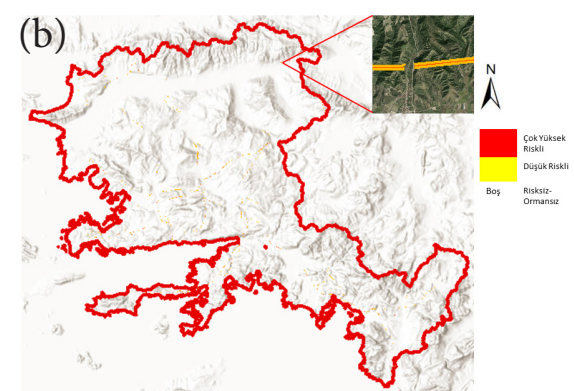


ladığg görülmüştür. Bu nedenle enerji nakil hatlarında 0-10 $\mathrm{m}$ arası zon en riskli alandır (Tablo 10). Ancak yüksek gerilim hatlarının kopması nedeniyle de yangın çıkabileceği düşünüldüğünde 10-50 m arası ikinci derece riskli olarak düşünülebilir.

\subsection{Kriter değerlendirme tablosunun oluşturulması ve risk indeksinin hesaplanması}

CBS ile analiz edilen kriterler ve arazi çalışmaları ile tespit edilen değer aralıkları kullanılarak kriter değerlendirme tablosu oluşturulmuştur (Tablo 11).

Tablo 11. Orman yangını riski kriterler tablosu

Table 11. Forest fire risk criteria table

\begin{tabular}{|c|c|c|c|c|c|}
\hline Kriterler & $\begin{array}{c}\text { Kriter } \\
\text { Ağırlığ } 1\end{array}$ & Alt kriterler & Kriter sinıflar1* & $\begin{array}{c}\text { Risk } \\
\text { Derecesi }\end{array}$ & Risk sinıfı \\
\hline \multirow{16}{*}{ Bitki örtüsü } & \multirow{16}{*}{7} & \multirow{7}{*}{ Ağaç türü } & Kızılçam & 5 & Çok Yüksek Riskli \\
\hline & & & Karaçam & 4 & Yüksek Riskli \\
\hline & & & Fistıkçamı & 3 & Orta Riskli \\
\hline & & & Maki & 3 & Orta Riskli \\
\hline & & & Okaliptüs & 2 & Düşük Riskli \\
\hline & & & Meşe & 2 & Düşük Riskli \\
\hline & & & Diğer Türler & 1 & Çok Düşük Riskli \\
\hline & & \multirow{4}{*}{ Kapalıl1k } & Sıkışık Kap. “3” & 5 & Çok Yüksek Riskli \\
\hline & & & Iş1kl1 Kap. "0" & 4 & Yüksek Riskli \\
\hline & & & Normal Kap. “2” & 3 & Orta Riskli \\
\hline & & & Gevşek Kap. "1” & 2 & Düşük Riskli \\
\hline & & \multirow{5}{*}{ Çağ sınıfları } & b "sirıklık/direklik" & 5 & Çok Yüksek Riskli \\
\hline & & & c "ince ağaçlık" & 4 & Yüksek Riskli \\
\hline & & & a "gençlik/sıklık" & 3 & Orta Riskli \\
\hline & & & d "orta ağaçl1k" & 2 & Düşük Riskli \\
\hline & & & e "kalın ağaçlık" & 1 & Çok Düşük Riskli \\
\hline \multirow{16}{*}{ Topoğrafya } & \multirow{16}{*}{5} & \multirow{4}{*}{ Eğim } & $0-20$ & 5 & Çok Yüksek Riskli \\
\hline & & & $21-30$ & 3 & Orta Riskli \\
\hline & & & $31-50$ & 2 & Düşük Riskli \\
\hline & & & $>51$ & 1 & Çok Düşük Riskli \\
\hline & & \multirow{8}{*}{ Bak1 } & G & 5 & Çok Yüksek Riskli \\
\hline & & & GB & 5 & Çok Yüksek Riskli \\
\hline & & & GD & 5 & Çok Yüksek Riskli \\
\hline & & & B & 4 & Yüksek Riskli \\
\hline & & & $\mathrm{D}$ & 3 & Orta Riskli \\
\hline & & & KB & 2 & Düşük Riskli \\
\hline & & & KD & 2 & Düşük Riskli \\
\hline & & & $\mathrm{K}$ & 1 & Çok Düşük Riskli \\
\hline & & \multirow{4}{*}{ Rakım } & $0-400 \mathrm{~m}$ & 5 & Çok Yüksek Riskli \\
\hline & & & $401-1000 \mathrm{~m}$ & 3 & Orta Riskli \\
\hline & & & $1000-1500 \mathrm{~m}$ & 2 & Düşük Riskli \\
\hline & & & $>1500 \mathrm{~m}$ & 1 & Çok Düşük Riskli \\
\hline \multirow{12}{*}{$\begin{array}{c}\text { İnsan } \\
\text { faaliyetlerine } \\
\text { mesafe }\end{array}$} & \multirow{12}{*}{3} & \multirow{4}{*}{$\begin{array}{l}\text { Tarım alanlarına } \\
\text { mesafe }\end{array}$} & $0-25 \mathrm{~m}$ & 5 & Çok Yüksek Riskli \\
\hline & & & $25-100 \mathrm{~m}$ & 3 & Orta Riskli \\
\hline & & & $100-500 \mathrm{~m}$ & 2 & Düşük Riskli \\
\hline & & & $500-1000 \mathrm{~m}$ & 1 & Çok Düşük Riskli \\
\hline & & \multirow{4}{*}{$\begin{array}{c}\text { Yerleşim yerlerine } \\
\text { mesafe }\end{array}$} & $0-50 \mathrm{~m}$ & 5 & Çok Yüksek Riskli \\
\hline & & & $50-200 \mathrm{~m}$ & 3 & Orta Riskli \\
\hline & & & $200-500 \mathrm{~m}$ & 2 & Düşük Riskli \\
\hline & & & $0-25 \mathrm{~m}$ & 5 & Çok Yüksek Riskli \\
\hline & & \multirow[t]{2}{*}{ Yollara mesafe } & $25-100 \mathrm{~m}$ & 3 & Orta Riskli \\
\hline & & & $100-500 \mathrm{~m}$ & 2 & Düşük Riskli \\
\hline & & \multirow{2}{*}{$\begin{array}{l}\text { Enerji nakil hatla- } \\
\text { rina mesafe }\end{array}$} & $0-10 \mathrm{~m}$ & 5 & Çok Yüksek Riskli \\
\hline & & & $10-50 \mathrm{~m}$ & 3 & Orta Riskli \\
\hline
\end{tabular}

* Değer aralıkları dışında kalan alanlarda risk sıfır (0) kabul edilmiştir. 
Kriter tablosu kullanılarak Erten ve arkadaşları (2005) tarafindan oluşturulan model ve kullandıkları denklem baz alınarak, Orman Yangını Risk İndeksi RS) aşağıdaki denklemdeki gibi hesaplanmıştır:

$$
\begin{gathered}
R S=7 x(A t+K p+C s s)+5 x(E g+B a+R a)+ \\
3 x(T a+Y e+Y o+E n)
\end{gathered}
$$

Denklemde "RS" risk indeksini, "At" ağaç türünü, "Kp" meşcere kapalılı̆̆ını, "Çs" gelişim çağını,
"Eg" eğimi, "Ba" bakıyı, "Ra" rakımı, "Ta" tarım alanlarına mesafeyi, "Ye" yerleşim yerlerine mesafeyi, "Yo" yollara mesafeyi ve "En" enerji nakil hatlarına mesafeyi ifade etmektedir.

Kriter tablosu ve risk indeksi kullanılarak sonuçta ArcGIS 10 programı mekansal analiz modülünde Muğla OBM çok kriterli orman yangını risk haritası oluşturulmuştur (Şekil 8).

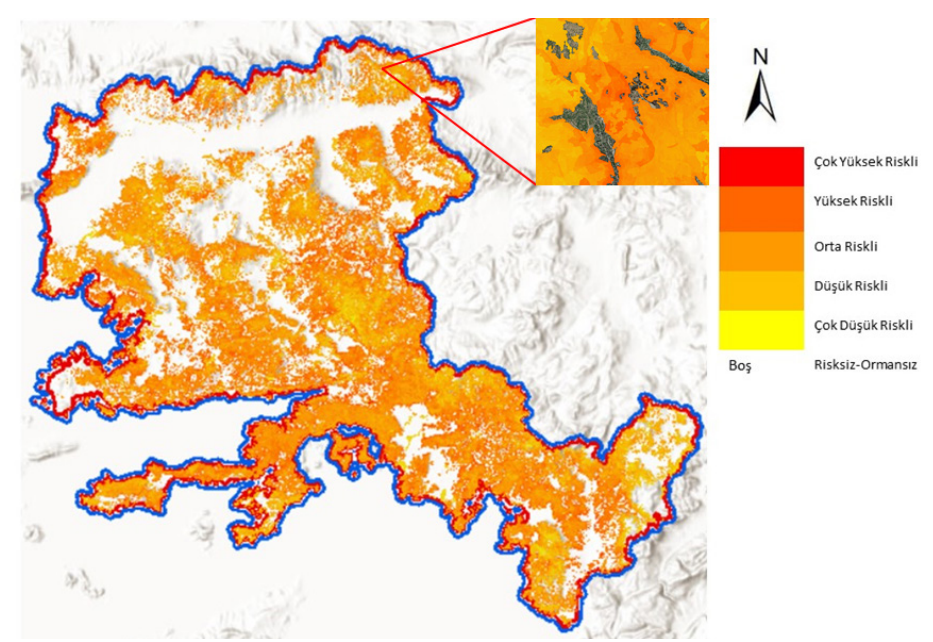

Şekil 8. Muğla OBM çok kriterli orman yangını risk haritası

Figure 8. Muğla Regional Directorate of Forestry multi-criteria forest fire risk map

Orman yangını risk haritası incelendiğinde; en yüksek orman yangını riskinin, kızılçamın baskın tür olduğu, "3” kapalı, "b” gelişim çapında, \%0-20 eğim aralığında ve güney bakıda bulunan, 0-400 $\mathrm{m}$ rakımlı ve insan faaliyetlerine en yakın durumdaki alanlarda olduğu görülmektedir. İnsan faaliyetlerinin orman alanlarıly iç içe girdiği Muğla OBM'nde orman yangını riskinin yüksek olduğu alanların genişliği şaşırtıcı değildir.

\section{Sonuç ve Öneriler}

Çalışma, Muğla Orman Bölge Müdürlüğü baz alınarak, Türkiye'de orman yangını riskinin analizinde daha doğru sonuçlar alınmasını sağlamak ve arazi ölçümlerinin de yardımıyla mümkün olduğu kadar objektif kriter değerlendirmeleri yapılması konusunda bir model oluşturmak hedefiyle yapılmıştır.

Ayrıca bu çalışma CBS kullanımının orman yangını riski analizindeki etkisini de göstermektedir. Mekansal analiz sonuçlarında her bir kriter ayrı ayrı orman yangın riskine sahiptir. Ancak kriterlerin beraber etki ettiği koyu renkli bölgelerde orman yangınları için kriterler özelinde önlemler alınması elzemdir. Örneğin ziraat alanları, yerleşim yerleri ve maden ocaklarının beraber etki ettiği bir alanda hem anız yakma, hem yerleşim yeri yangınları, hem de maden ocağı kazaları açısından ayrı ayrı tedbirler alınarak toplam riskin azaltılması için çalışmalar yapılmalıdır. Bu alanlar, orman yangınlarına sebep olabilecek kriterlerin orman arakesitindeki temas noktalarını ifade etmektedir. Orman yangınlarının başlama ihtimalinin yüksek olduğu alanlar buralardır. Alınacak tedbirler ve yangın söndürme ekiplerinin organizasyonu da bu alanlarda yapılmalıdır.

Yangın risk haritasının oluşumuna etki eden kriterlere bağlı olarak alınacak özel tedbirler, yangınların önlenmesi ve erken müdahalesine önemli katk1 sağlayabileceği için Orman Genel Müdürlüğü’nün orman yangınlarıyla mücadele bütçesinde önemli bir tasarrufa da vesile olabilecektir.

Orman yangınlarını önceden tahmin etmek çok zordur, ancak yangın bilgi sistemleri ve yangın riski haritaları yardımıyla orman yangınlarının potansiyel zararları en aza indirilebilir (Akbulak ve ark., 2018). Yangın Tehlike Oranları Sistemi'nin bir parçası olarak orman yangını riski haritaları, meteorolojik risk haritaları ile birlikte kullanılarak dinamik hale getirilebilir ve karar vericiye alınacak tedbirler ve ekip organizasyonu hususlarında büyük destek sağlayabilir (Bilgili ve ark., 2001).

Orman yangınları, genellikle insan faaliyetleri so- 
nucu olarak ortaya çıkmaktadır. Bu nedenle risk haritalarının gösterdiği yangına sebep olabilecek kriterler konusunda vatandaşların eğitilmesi ve bilinçlendirmesi de gerekmektedir. Ayrıca yangın riskinin yüksek olduğu alanlarda yakıt miktarını azaltmak için yol kenarları temizlenmeli, rekreasyon alanlarının kullanımına ilişkin düzenlemeler yapılmalı ve yangın riskinin azaltılması için yerel halk uymaları beklenen kurallar hakkında bilgilendirilmelidir (Akbulak ve ark., 2018).

\section{Kaynaklar}

Akay, A.E. Şahin, H., 2019. Forest fire risk mapping by using GIS techniques and AHP method: A Case Study in Bodrum (Turkey). Eur. J. Forest. Eng., 5(1): 25-35

Akbulak, C., Tatli, H., Aygün, G., Sağlam, B. 2018. Forest fire risk analysis via integration of GIS, RS and AHP: The Case of Çanakkale, Turkey, Journal of Human Sciences, 15(4): 2127-2143

Archibald, S., Lehmann, C. E. R., Gómez-Dans, J. L., Bradstock, R. A., 2013. Defining pyromes and global syndromes of fire regimes, Proceedings of the National Academy of Sciences 110: 6442-6447

Bilgili, E., Sağlam, B., Başkent, E.Z. 2001. Yangın amenajmanı planlamalarında yangın tehlike oranları ve Coğrafi Bilgi Sistemleri. KTÜ Orman Fakültesi, Fen ve Mühendislik Dergisi, 4(2): 88-97

Doussi, M.A., Thanos, C.A., 1994. Postfire regeneration of hardseeded plants: Ecophysology of seed germination. Proceedings of the 2nd International Conference of Forest Fire Research, Coimbra, Vol II, D 25, pp. 1035-1044

Erten, E., Kurgun, V., Musaoglu, N. 2004. Forest Fire Risk Zone Mapping from Satellite Imagery and GIS: A Case Study, XX. Congress of the International Society for Photogrammetry and Remote Sensing (ISPRS), July, Istanbul, Turkey, Proceedings: 12-25

Erten, E., Kurgun, V., Musaoğlu, N. 2005. Uzaktan A1gılama ve Coğrafi Bilgi Sistemleri Kullanarak Orman Yang1nı Bilgi Sisteminin Kurulması, TMMOB Harita ve Kadastro Mühendisleri Odası 10. Türkiye Harita Bilimsel ve Teknik Kurultayı. Ankara

Genç, M. 2012. Silvikültürün Temel Esasları, SDÜ Orman Fakültesi, Yayın No: 44, s30-37

Jaiswal, R.K., Mukherjee, S., Raju, D.K., Saxena, R., 2002. Forest fire risk zone mapping from satellite imagery and GIS. Int Journal of Applied Earth Observation and Geoinformation, 4(2002): 1-10

Karabulut, M., Karakoç, A., Gürbüz, M., Kızılelma, Y. 2013. Coğrafi Bilgi Sistemleri kullanarak Başkonuş Dağında (Kahramanmaraş) orman yangını risk alanlarının belirlenmesi, Uluslararası Sosyal Araştırmalar Dergisi, 6(24): 171-179

Mavsar, R., Cabán, A.G., Varela, E., 2013. The state of development of fire management decision support systems in America and Europe. Forest Policy and Economics, 29: 45-55

Moreira, F., Vallejo, R., 2009. What to do after fire? Post-fire restoration. In Birot, Y., (ed.), Living with Wild fires: What science can tell us, A contribution to the science - Policy dialoque, EFI Discussion Paper, 15: 53-58

OGM, 2020a, "2010-2019 Y1lları Arasında Meydana Gelen Orman Yangınlarının Çıkış Sebeplerine Dağılımı”. Orman Yangınları Değerlendirme Raporu, 2020. Orman Yangınlarıyla Mücadele Daire Başkanlığı. 48s

OGM, 2020b, “2010-2019 Y1llar1 Arasinda meydana Gelen Orman Yangını verileri”. Orman Yangınlarıyla Mücadele Dairesi yangın sıralaçları, 2020. Orman Yangınlarıyla Mücadele Dairesi Başkanlığı veritabanı

OGM, 2020c, “2010-2019 Y1llar1 Arasında Meydana Gelen Orman Yangınlarının Bölge Müdürlüklerine Dağılımı”. Orman Yangınları Değerlendirme Raporu, 2020. Orman Yangınlarıyla Mücadele Daire Başkanlığı. 32s

Pausas, J. G., 2004. Changes in fire and climate in the eastern Iberian Peninsula (Mediterranean basin), Climatic Change, 63: 337-350

Pausas, J. G., Keeley, J. E., 2014. Abrupt climate-independent fire regime changes, Ecosystems, 17: 1109-1120

Sağlam, B., Ertuğrul, B., Durmaz, B.D., Kadıŏulları, A.İ., Küçük, Ö., 2008. Spatio-temporal analysis of forest fire risk and danger using LANDSAT imagery. Sensors, 8: $3970-3987$

Sivrikaya, F., Akay, A.E., Oğuz, H., Yenilmez, N., 2011. Mapping Forest Fire Danger Zones Using GIS: A Case Study from Kahramanmaraş. 6th International Symposium on Ecology and Environmental Problems. 17-20 November, Antalya

Skidmore, A. K., 1997. Modelling topographic variation in solar radiation in a GIS environment: research article. Inl. Journal of Geographical Inf. Science, 11(5): 475-497

Tavşanoğlu, Ç., 2017. Yangın Coğrafyası: Vejetasyon yangınlarının ve ekolojik sonuçlarının alansal dağılımı. Kebikeç, 2017/43: 289-300

Taylor, S., W., Alexander, M., E., 2003. Considerations in Developing a National Forest Fire Danger Rating System. Paper Presented at the XII World Forestry Congress, Quebec, Canada, 9s.

URL-1: Muğla Orman Bölge Müdürlüğü genel bilgiler (Erişim tarihi: 06/03/2020)

URL-2: Muğla Orman Bölge Müdürlüğü orman varlığ1. https://muglaobm.ogm.gov.tr/ Sayfalar/ Ormanlarimiz / OrmanVarligi.aspx (Erişim tarihi: 06/03/2020)

Van Wilgen, B., W., Burgan, R., E., 1984. Adaptation of the United States fire danger rating system to Fynbos conditions, Part II, Historic Fire Danger in the Fynbos Biome, South African Forestry Journal, 129: 66-78 